\title{
Promoting the removal of coal-fired fine particles by the coupling of different vortex sheets in chemical-turbulent agglomeration
}

Zongkang Sun, Linjun Yang, Xiuwei Ma, Xin Wu, and Hao Wu

Energy Fuels, Just Accepted Manuscript • DOI: 10.1021/acs.energyfuels.0c02151 • Publication Date (Web): 08 Jul 2020

Downloaded from pubs.acs.org on July 22, 2020

\section{Just Accepted}

"Just Accepted" manuscripts have been peer-reviewed and accepted for publication. They are posted online prior to technical editing, formatting for publication and author proofing. The American Chemical Society provides "Just Accepted" as a service to the research community to expedite the dissemination of scientific material as soon as possible after acceptance. "Just Accepted" manuscripts appear in full in PDF format accompanied by an HTML abstract. "Just Accepted" manuscripts have been fully peer reviewed, but should not be considered the official version of record. They are citable by the Digital Object Identifier (DOI®). "Just Accepted" is an optional service offered to authors. Therefore, the "Just Accepted" Web site may not include all articles that will be published in the journal. After a manuscript is technically edited and formatted, it will be removed from the "Just Accepted" Web site and published as an ASAP article. Note that technical editing may introduce minor changes to the manuscript text and/or graphics which could affect content, and all legal disclaimers and ethical guidelines that apply to the journal pertain. ACS cannot be held responsible for errors or consequences arising from the use of information contained in these "Just Accepted" manuscripts. 

computational fluid dynamics (CFD) method to explore the promotion mechanism by different vortex sheets.

19 The results proved that the coupling of vortex sheets with different structures in chemical-turbulent $\$$ School of Energy and Mechanical Engineering, Nanjing Normal University, Nanjing 210042, China

9

them. In this work, the coupling of vortex sheets with different structures in chemical-turbulent agglomeration was proposed to generate more disordered flow field for better particle agglomeration and removal effect. Three turbulent agglomerators containing different vortex sheets were designed and manufactured, and the particle number concentration, size distribution, as well as the particle removal efficiency after chemical-turbulent agglomeration with different turbulent agglomerators were investigated by experiments. The results showed that the turbulent agglomerator with the coupling of different vortex sheets can effectively promote the agglomeration and removal effect of fine particles, the number of fine particles below $0.1 \mu \mathrm{m}$ decreased significantly, and the number and mass concentration of fine particles after ESP also decreased. In addition, the flow field distribution, the motion and residence time of fine particles in different turbulent agglomerators were simulated using agglomeration can make the turbulent flow field more disordered, enhance the relative movement of fine particles, and extend their residence time in the flow field, so as to promote the agglomeration and removal 
22 effect.

\section{1. INTRODUCTION}

24 Lots of fine particles are produced by coal combustion in kinds of industrial process, such as power generation,

25 cement production, steel smelting, and so on. ${ }^{1}$ In China, more than $60 \%$ of coal are burned for electricity, ${ }^{2}$ and

26 it produces large amounts of fly ash, which contains plenty of fine particles with aerodynamic diameter less than

$272.5 \mu \mathrm{m}\left(\mathrm{PM}_{2.5}\right)$. The traditional dust removal equipment for coal-fired flue gas mainly includes the electrostatic

28 precipitator (ESP), fabric filter (FF) and cyclone. Due to the small particle size and special aerodynamic

29 characteristics, the removal efficiency of $\mathrm{PM}_{2.5}$ is relatively low. ${ }^{3,4}$ Therefore, large quantities of fine particles

30 escape into the atmosphere and cause serious air pollution, especially in urban areas. ${ }^{5-7}$ Besides, the fine particles

31 can absorb many kinds of toxic substances from the atmosphere due to their large specific surface area, which

32 is harmful to human health when they enter into the human respiratory system. ${ }^{8-11}$

33 In order to improve the removal efficiency of fine particles by existing dust removal equipment, many kinds

34 of pretreatment technologies have been proposed, including electric agglomeration, ${ }^{12,13}$ chemical

35 agglomeration, ${ }^{14,15}$ heterogeneous-condensation agglomeration, ${ }^{16,17}$ turbulent agglomeration, ${ }^{18,19}$ and acoustic

36 agglomeration. ${ }^{20,21}$ The fine particles can agglomerate into larger ones after these agglomeration techniques,

37 which is beneficial to the capture and removal of them. Besides, kinds of coupling agglomeration techniques

38 have been proposed to further promote the agglomeration and removal of fine particles in recent years, including

39 the acoustic agglomeration combined with vapor condensation, ${ }^{22}$ corona discharge combined with acoustic wave, ${ }^{23}$ acoustic agglomeration combined with seed droplets, ${ }^{24-26}$ and chemical spray combined with turbulent

41 agglomeration..$^{27,28}$ Among them, the chemical spray combined with turbulent agglomeration (chemical-

42 turbulent agglomeration) can effectively improve the agglomeration effect of fine particles. During the particle 
agglomeration process, the agglomeration effect depends on the coagulation efficiency and collision times of them. The coagulation efficiency refers to the probability that particles can agglomerate together after a collision, which is affected by their surface properties, such as humidity, viscosity and electrostatic effect. ${ }^{29}$ In the single chemical agglomeration, fine particles collide with the chemical droplets, and they are wetted by the droplets or covered with liquid films on their surfaces, which is conducive to enhancing the surface interaction between them and improving the coagulation efficiency. However, the fine particles with wetted surface can only flow along a straight line with the flue gas, and there are few collisions between them, which limits the final agglomeration effect. Compared with that, the turbulent flow field is added after the chemical spray in chemicalturbulent agglomeration, the fine particles collide with the chemical droplets firstly and are wetted, and then enter into the turbulent flow field for frequent collisions. The injection of chemical droplets improves the coagulation efficiency of fine particles, and the turbulent flow field can ensure enough collisions between them, so as to improve their final agglomeration effect.

55 Turbulent flow field can cause collisions between fine particles. As the particle sizes in fly ash are not same, their mass and inertia are different, and the following behaviors to fluid of them are also different. The turbulence

57 in flow field can produce large velocity gradients in the fluid, which can make the particles with different sizes have different motion velocities and trajectories, so as to promote their collision. Asanakham et al. studied the

59 promotion effect of different bluff bodies on the agglomeration of submicron particles, and the result showed that the flat-plate and cylindrical ones can reduce the number of fine particles by $27 \%$ and $17 \%$ respectively. ${ }^{30}$

61 Afkhami et al. investigated the influence of different particle surface energies and fluid turbulence on particle agglomeration behavior by the coupled large eddy simulation. ${ }^{31}$ Breuer et al. simulated the agglomeration of dry (electrostatically neutral) particles in turbulent gas flows in the framework of an Eulerian-Lagrangian approach 
relying on first-principles collision and agglomeration models, and they found that the enhanced agglomeration model and the newly introduced structure models can realistically predict the physical behavior of the agglomeration process in turbulent particle-laden shear flows. ${ }^{32}$ Generally, the more disordered the turbulent flow field, the greater the difference in the movement of fine particles, and the more frequent collisions between them. In the chemical-turbulent agglomeration, the vortex sheets are applied to generate turbulent flow field, and the coupling of different vortex sheets can generate vortexes with different intensities and scales in the flow field simultaneously, which makes the flow and distribution pf flue gas more disordered and the velocities and trajectories of fine particles more different, so as to further promote the collision and agglomeration of them. different vortex sheets in chemical-turbulent agglomeration was proposed, the turbulent agglomerators containing two different kinds of vortex sheets or only containing the same kind of vortex sheets were designed and manufactured. The particle number concentration, size distribution, as well as the particle removal efficiency after chemical-turbulent agglomeration with different turbulent agglomerators were investigated by experiments.

78 turbulent agglomerators were analyzed by simulation to research the promotion mechanism of different vortex sheets on the agglomeration and removal of fine particles.

\section{2. EXPERIMENTAL SECTION} agglomeration system, turbulent agglomeration system, ESP and induced draft fan in the chemical-turbulent agglomeration system. The air was heated by the gas heater and then flowed into the buffer vessel, in which the

2.1. Experimental set-up. As shown in Figure 1, it mainly consisted of the gas heater, buffer vessel, chemical

4 fly ash was provided by a solid aerosol generator (SAG 410/U, Topas Ltd., Germany) and the stirrer can make 
the particle evenly distributed in the flue gas. The fly ash was sampled from a coal-fired power plant and contained plenty of fine particles. Then the flue gas containing fine particles passed through the chemical and turbulent agglomeration system in turn, and then entered the ESP, where the fine particles were captured and removed. During the experiment, the temperature of original flue gas was maintained at $150{ }^{\circ} \mathrm{C}$, the gas velocity in the flue was $10 \mathrm{~m} / \mathrm{s}$, the applied rectifier voltage of the ESP was set as $-40 \mathrm{kV}$. Besides, the electrical low pressure impactor (ELPI+, Dekati Co. Ltd., Finland) and aspirated isokinetic sampler (WJ-60B, Laoying Ltd., can measure fine particles in the size range from $6 \mathrm{~nm}$ to $10 \mu \mathrm{m}$ through a 14-stage cascade low-pressure impactor, the result of which can represent the concentration of $\mathrm{PM}_{10}$ (fine particles with aerodynamic diameter less than $10 \mu \mathrm{m}$ ) in flue gas. The microscopic morphology of fine particle samples was observed by a field emission scanning electron microscopy (Ultra Plus, Zeiss Ltd., Germany), which also contained an energy dispersive spectrometer (EDS) and can measure the element composition of them.

99 xanthan gum (XTG) and sodium dodecyl sulfonic salt (SDS) were selected as agglomerant and wetting agent, which dissolved in water to form chemical agglomeration solution. The mass concentrations of XTG and SDS were $0.05 \%$ and $0.025 \%$, and the flow rate of chemical spray was set as $10 \mathrm{~L} / \mathrm{h}$. The nozzle was a two-fluid

2.2. Chemical agglomeration system. The chemical agglomeration system mainly consisted of the evaporation chamber, atomizing nozzle, agglomeration solution tank, metering pump and air compressor. The atomizing nozzle, the pressure of compressed air entering it was controlled at $0.3 \mathrm{MPa}$ by the air compressor,

104 particle dynamic analyzer (PDA, Dantec Dynamics Co. Ltd., Denmark). It showed that the sizes of atomized 105 droplets were all smaller than $100 \mu \mathrm{m}$ and the average droplet size was about $20 \mu \mathrm{m}$, which indicated the 
106 atomization effect was excellent. Moreover, the height and diameter of the evaporation chamber were 4000 and

$107377 \mathrm{~mm}$ respectively.

108 2.3. Turbulent agglomeration system. The turbulent agglomeration system consisted of three turbulent

109 agglomerators $(\# 1, \# 2, \# 3)$, in which the vortex sheets had different structures and arrangements. They were

110 arranged in parallel, and the gas flow path can be easily changed by adjusting the valves in front of them, so as

111 to investigate the particle agglomeration effect by different turbulent agglomerators. All turbulent agglomerators

112 had the same external structure, which was a stainless steel tube with square section. The length of it and the

113 side length of its square section were 1320 and $100 \mathrm{~mm}$ respectively. In this study, two types of vortex sheets

114 were made, the structures and arrangements of them in three turbulent agglomerators are shown in Figure 3. One

115 kind of the vortex sheets had a z-type section, the width of it in the vertical direction of gas flow was $30 \mathrm{~mm}$,

116 and the circumscribed circle diameter of it was $60 \mathrm{~mm}$. The other kind of vortex sheets had a cross-type section,

117 the length and width of which were both $20 \mathrm{~mm}$. In turbulent agglomerator \#1, the two types of vortex sheets

118 were arranged simultaneously, with 2 z-type and 12 cross-type vortex sheets as a group, and there were 2 groups

119 in it. In turbulent agglomerator \#2, the vortex sheets were all z-type ones, and 16 vortex sheets were arranged

120 alternately in 2 columns. In turbulent agglomerator \#3, the vortex sheets were all cross-type ones, and there were

12116 pairs of them arranging abreast in 2 columns.

122 3. RESULTS AND DISCUSSION

123 3.1. Particle agglomeration effect after different turbulent agglomerators. In order to investigate the

124 particle agglomeration effect, the particle number concentrations before and after the chemical-turbulent

125 agglomeration system were measured, as seen in Figure 4. During the experiment, the gas temperature and

126 particle concentration after the buffer vessel were remained constant, and the test points were arranged before 
the evaporation chamber and after the turbulent agglomerator. The number concentration of fine particles in original flue gas was $8.92 \times 10^{6} 1 / \mathrm{cm}^{3}$, and it reduced to $4.50 \times 10^{6}, 5.01 \times 10^{6}$ and $5.47 \times 10^{6} 1 / \mathrm{cm}^{3}$ after the turbulent agglomerator \#1, \#2 and \#3, respectively. In the process of particle collision and agglomeration, some

130 fine particles would contact and aggregate to form a large particle, so as to reduce the number of them. On the

131 other hand, some fine particles would adhere on the coarse particles with diameter larger than $10 \mu \mathrm{m}$ and get out

132 of the range of $\mathrm{PM}_{10}$, which can also cause a decrease in the number of fine particles. Defining the ratio of

133 particle number concentration decrement in flue gas as the agglomeration efficiency, and it can be calculated

134 that the fine particle agglomeration efficiencies after turbulent agglomerator \#1, \#2 and \#3 were 49.5\%, 43.8\%

135 and $38.7 \%$, respectively. The result indicated that the collision and agglomeration of fine particles can be

136 promoted under the combined effect of chemical droplets and turbulent flow field, the particle number

137 concentration in flue gas can be reduced, and the turbulent agglomerator \#1 containing different kinds of vortex

138 sheets in it had the best effect.

139 What's more, the particle size distributions after chemical-turbulent agglomeration with different turbulent

140 agglomerators were also measured, shown in Figure 5. It can be seen that in original flue gas, most of the particles

141 were less than $0.1 \mu \mathrm{m}$ in diameter, accounting for about $95.8 \%$, and the particle number decreased rapidly with

142 the increase of particle size. After chemical-turbulent agglomeration, the number concentrations of fine particles

143 in different size ranges all decreased, especially within the range of $0.1 \mu \mathrm{m}$. In this range, the total number

144 concentration of fine particles was $8.53 \times 10^{6} 1 / \mathrm{cm}^{3}$ in original flue gas, and it reduced to $4.17 \times 10^{6}, 4.51 \times 10^{6}$

145 and $5.34 \times 10^{6} 1 / \mathrm{cm}^{3}$ after the turbulent agglomerator \#1, \#2 and \#3, respectively. It indicated that the chemical-

146 turbulent agglomeration mainly promoted the collision and agglomeration of fine particles below $0.1 \mu \mathrm{m}$, so as

147 to reduce the number of $\mathrm{PM}_{10}$. Consequently, the experimental result proved that the turbulent agglomerator \#1 
148 with the coupling of different vortex sheets in flow field could promote the agglomeration of fine particles below

$1490.1 \mu \mathrm{m}$ more effectively, so as to get the best agglomeration effect for fine particles.

150

3.2. Characteristics of fine particle agglomerates. The micromorphology and composition changes of fine

151 particles were detected to analyze the chemical-turbulent agglomeration process, shown in Figure 6. In original

152 flue gas, the particles were all spherical with smooth surface, and no obvious connections were observed between

153 them (Figure 6a). After chemical-turbulent agglomeration, there were many fine particles attached to each other,

154 and they were connected by flocculent structures to form stable large-size aggregates (Figure 6b). It can be

155 inferred that during the chemical-turbulent agglomeration process, the particles collided with the chemical

156 droplets and were wetted or covered with liquid films on their surfaces. After that, these particles collided and

157 agglomerated together following the flue gas in the subsequent turbulent flow field. With the evaporation of

158 water, the chemical agglomeration agent connected many fine particles together by flocculent structure to form

159 large aggregates. To further prove that, the compositions of fine particles before and after agglomeration were

160 also tested by the EDS, shown in Figure 6c. In original particles, the main elements were C, O, Al, Si and Fe,

161 accounting for $96.7 \%$ in total. After the chemical-turbulent agglomeration, the types of main elements and the

162 total proportion of them remained almost same, which accounted for $97.4 \%$. However, the proportion of different

163 elements changed, the proportion of $\mathrm{C}$ increased from $12.18 \%$ to $19.64 \%$, and that of $\mathrm{O}, \mathrm{Al}, \mathrm{Si}$ and $\mathrm{Fe}$ all dropped

164 slightly. It can be explained that the agglomerant XTG $\left(\mathrm{C}_{35} \mathrm{H}_{49} \mathrm{O}_{29}\right)$ and wetting agent $\mathrm{SDS}\left(\mathrm{C}_{12} \mathrm{H}_{25} \mathrm{SO}_{4} \mathrm{Na}\right)$ in

165 chemical agglomeration solution both contained a higher proportion of $\mathrm{C}$ than fine particles, and lots of chemical

166 droplets adhered on the particle surface during the agglomeration process, so the final aggregates contained a

167 higher proportion of $\mathrm{C}$ than original fine particles, and the proportion of other elements decreased

168 correspondingly. The results indicated that the chemical droplets changed the surface characteristics of fine 
169 particles, which was conducive to their agglomeration in subsequent turbulent flow field through collision, so as

170 to form aggregates with large sizes.

171 3.3. Particle removal effect by ESP after different turbulent agglomerators. The particle concentrations

172 after ESP were measured to research the promotion effect of different turbulent agglomerators on particles

173 removal, shown in Figure 7. The original number concentration of fine particles was $8.92 \times 10^{6} 1 / \mathrm{cm}^{3}$, and it

174 decreased to $1.94 \times 10^{6} 1 / \mathrm{cm}^{3}$ after ESP without any agglomeration pretreatment. When the chemical-turbulent

175 agglomeration system was added in front of ESP, the number concentration of fine particles at the outlet of ESP

176 further decreased to $6.36 \times 10^{5}, 1.19 \times 10^{6}$ and $1.56 \times 10^{6} 1 / \mathrm{cm}^{3}$ with turbulent agglomerator \#1, \#2 and \#3,

177 which respectively decreased about $67.2 \%, 38.7 \%$ and $19.6 \%$ than that only by ESP. On the other hand, the

178 original mass concentration of fine particles were $308 \mathrm{mg} / \mathrm{m}^{3}$, and it decreased to $26.2 \mathrm{mg} / \mathrm{m}^{3}$ after ESP. When

179 the chemical-turbulent agglomeration system was added, it further decreased to $10.3,19.1$ and $22.5 \mathrm{mg} / \mathrm{m}^{3}$ with

180 turbulent agglomerator $\# 1, \# 2$ and $\# 3$, respectively. It can be calculated that the particle mass concentration after

181 ESP reduced about $60.5 \%, 27.1 \%$ and $14.1 \%$. Same as the agglomeration effect, the turbulent agglomerator \#1

182 containing different vortex sheets had the best promotion effect for fine particles removal, and the maximum

183 reduction on number and mass concentrations of fine particles reached $67.2 \%$ and $60.5 \%$ respectively after ESP.

184 It can be explained that due to the effective collision and agglomeration of fine particles in turbulent

185 agglomerator \#1, more fine particles connected to each other to form large aggregates, which increased the

186 electrical charge quantity and mobility of particles in the electric field of ESP, ${ }^{33}$ thus enhancing the capture effect

187 of them.

188 Moreover, to further compare the removal effect of fine particles with different turbulent agglomerators, the 189 particle stage removal efficiencies were measured, shown in Figure 8. The ratio of particle number concentration 
190 decrement on certain stage of ELPI+ was defined as the particle stage removal efficiency, and it included 14

191 stages in total. It can clearly indicate the removal efficiency difference of fine particles with different sizes. The

192 result showed that the fine particles removal efficiency by ESP was relatively low in the range of less than 1.0

$193 \mu \mathrm{m}$, and the lowest removal efficiency was $64.1 \%$ on the 3 th stage, where the $\mathrm{D}_{50}$ (diameter of particle as the

194 cumulative distribution reached 50\%) was $0.04 \mu \mathrm{m}$. After the chemical-turbulent agglomeration, the removal

195 efficiency mainly increased in the range of less than $1.0 \mu \mathrm{m}$, the average removal efficiency increased from $79.4 \%$

196 to $92.4 \%, 86.3 \%$ and $83.0 \%$ with turbulent agglomerator \#1, \#2 and \#3. Accordingly, the chemical-turbulent

197 agglomeration mainly improved the removal of fine particles below $1.0 \mu \mathrm{m}$, thus improving the removal

198 efficiency of $\mathrm{PM}_{10}$, and the turbulent agglomerator \#1 had better effect on promoting the removal of fine particles

199 than \#2 and \#3.

200 3.4. Promotion mechanism of particle agglomeration by turbulent flow field. 3.4.1. Flow field

201 distributions in turbulent agglomerators. Through the contact of fine particles and chemical droplets, the surface

202 properties of fine particles have been changed and their coagulation efficiency is improved. After that, the key

203 to improve the final agglomeration efficiency is to increase the collision times between them. The turbulent flow

204 field can make fine particles have different motion trajectories, thus promoting their collision and agglomeration.

205 In order to illustrate the influence of different vortex sheets on the turbulent flow field, the flow field distributions

206 in three turbulent agglomerators were simulated using a CFD software package, Fluent, as seen in Figure 9.

207 Besides, the flow field distribution in a flue that didn't contain any vortex sheets and had the same external

208 structure as the turbulent agglomerators was also simulated. The flue gas was considered as continuous phase,

209 and the gas flow was calculated by the mass, momentum and energy conservation equations, which were solved

210 by Eulerian approach. The RNG $k-\varepsilon$ model was chosen to simulate the turbulent flow, and the standard wall 
211 equation was applied near the flue duct wall. ${ }^{34}$

212 During the calculation, the flue gas was regarded as ideal gas, and its temperature was set as $423 \mathrm{~K}$, velocity

213 was $10 \mathrm{~m} / \mathrm{s}$ and dynamic viscosity was $2.4 \times 10^{-5} \mathrm{~kg} / \mathrm{m} \cdot \mathrm{s}$. The result shows that in the flue without vortex sheets,

214 except for the low velocity near the flue wall due to the boundary layer effect, the velocity distribution of flue

215 gas is uniform in all positions, which is about $10 \mathrm{~m} / \mathrm{s}$ and basically the same as the inlet velocity. However, the

216 velocity distributions of flue gas in turbulent agglomerators are very disordered due to the existence of vortex

217 sheets. It can be seen that in the three turbulent agglomerators, the gas velocity in the area behind the vortex

218 sheets (backflow area) is generally below $5 \mathrm{~m} / \mathrm{s}$, while the gas flows very fast in the area between the two

219 columns of vortex sheets (main flow area), which reaches $20-30 \mathrm{~m} / \mathrm{s}$. The result indicates that the vortex sheets

220 can cause velocity difference at various positions in the flow field, which is easy to cause collisions between fine

221 particles. In addition, the flow field distributions in turbulent agglomerators containing different vortex sheets

222 are not same. In turbulent agglomerator \#1, large backflow areas are formed behind the z-type vortex sheets, and

223 the smaller ones are formed behind the cross-type ones. Moreover, the backflow areas behind different cross-

224 type vortex sheets are also different. The backflow area behind the cross-type vortex sheet is relatively large

225 when it is close to the z-type one, which means the two kinds of vortex sheets influence each other on generating

226 yortexes, making the flow field distribution more disordered. In turbulent agglomerator \#2, due to the same

227 structure of z-type vortex sheets, the size of each backflow area in the flow field is similar and there is almost

228 no interaction between them. The flow field distribution in turbulent agglomerator \#3 is similar to \#2, except

229 that the size of cross-type vortex sheet is small, so each backflow area is also small. When the flue gas encountered a vortex sheet during the flow in the turbulent agglomerator, due to the blocking effect of it, the flue 231 gas would bypass the vortex sheet and generated vortexes behind it. After that, the vortexes generated with large 
232 scales continually broke up and transformed into those with smaller scales until they disappeared. ${ }^{35}$ During the

233 process, the scale and intensity of the maximum vortex generated by the vortex sheets with different structures

234 was different at the beginning, which led to the different vortex distribution in subsequent flow field. When the

235 different kinds of vortex sheets were coupled in the turbulent agglomerator, the break and transformation of

236 vortexes in the flow field were more complicated due to the different scales and intensities of vortexes produced

237 by them, making the flow field distribution more disordered, which was more conducive to the collision and

238 agglomeration of fine particles with different sizes.

239 3.4.2. Motion of fine particles in turbulent agglomerators. The premise for collision and agglomeration

240 between fine particles is their relative movement. Under the influence of turbulent flow field, fine particles with

241 different sizes have different motion trajectories due to their own inertia and the dragging effect by flue gas,

242 which causes the relative movement and collision between them. In order to explore the promotion mechanism

243 of particle agglomeration by different vortex sheets in the flow field, the motion trajectories of fine particles with

244 different sizes in three turbulent agglomerators were calculated by simulation, which includes the diameter of

$2450.1,1.0,2.5$ and $10 \mu \mathrm{m}$. Besides, that in a flue with the same external structure but containing no vortex sheets

246 were also simulated as a comparison, shown in Figure 10. The discrete-phase model (DPM) was used to simulate

247 the movement of fine particles, and their trajectories were calculated by integrating the force balance on them.

248 According to the classical particle motion model proposed by Spalding, the drag force $\left(F_{\text {drag }}\right)$ and gravity $\left(F_{\text {gravity }}\right)$

249 were considered as major factors during the movement of fine particles in flue gas, and other external forces can

250 be ignored. ${ }^{36}$ The equilibrium equations of fine particles are expressed as: ${ }^{34}$

$251 \quad m_{\mathrm{p}} \frac{d v_{\mathrm{p}}}{d t}=F_{\text {drag }}+F_{\text {gravity }}$ 
$252 \quad F_{\text {drag }}=\frac{3}{4} m_{\mathrm{p}} \frac{\rho_{\mathrm{g}} C_{D}}{\rho_{\mathrm{p}} d_{\mathrm{p}}}\left|\overrightarrow{u_{\mathrm{p}}}-\vec{u}\right|$

$253 \quad F_{\text {gravity }}=m_{\mathrm{p}} \frac{\rho_{\mathrm{p}}-\rho_{\mathrm{g}}}{\rho_{\mathrm{p}}} \vec{g}$

254 where $m_{\mathrm{p}}$ and $d_{\mathrm{p}}$ are the mass and diameter of particles, $\overrightarrow{u_{\mathrm{p}}}$ and $\vec{u}$ are the velocity of particles and flow gas, $\rho_{\mathrm{p}}$ 255 and $\rho_{\mathrm{g}}$ are the density of particles and flow gas, and $C_{D}$ is the drag coefficient. The specific parameters used in 256 the simulation are shown in Table 1.

257 The result shows that in the flue without vortex sheets, fine particles with different sizes all flow uniformly in 258 a straight line along the $\mathrm{x}$-axis direction, and there is almost no fluctuation during the movement. This is due to 259 that no vortexes are generated in the flow field and it is a laminar flow. While, their motion in the turbulent flow 260 field is totally different. In three turbulent agglomerators, the smaller the particles sizes, the better their following 261 performance to the flue gas, and more of them can enter into the backflow areas behind the vortex sheets with 262 the flue gas (e.g. $0.1,1.0$ and $2.5 \mu \mathrm{m})$. The larger the particles sizes, the worse their following performance, and 263 they are more inclined to maintain their original movement and flow in the main flow area (e.g. $10 \mu \mathrm{m})$. The

264 motion of a particle in flow field is determined by the Stokes number $\left(S t_{K}\right)$ of it, which represents the ratio of

265 particle inertia and diffusion. The smaller the value is, the smaller the particle inertia is and the easier it is to

266 follow the fluid. On the contrary, the larger the value is, the greater the particle inertia is, and the less obvious

267 the particle's following effect to the fluid. It can be defined as the ratio of particle relaxation time scale to the

268 characteristic time scale of the turbulent flow, which is expressed as

$269 S_{t k}=\frac{\tau \mathrm{p}}{\tau \mathrm{K}}$

270 where $\tau_{\mathrm{p}}$ is the relaxation time scale of a particle, and $\tau_{\mathrm{k}}$ is the Kolmogorov time scale of turbulence as 271 characteristic time scale, which can be expressed in the following equations: 
$272 \quad \tau \mathrm{p}=\frac{1 \rho \mathrm{p} d_{\mathrm{p}}^{2}}{18 \rho \mathrm{f} \mu}$

$273 \tau \tau \mathrm{K}=\left(\frac{v^{3}}{\varepsilon}\right)^{\frac{1}{2}}$

274 where $d_{\mathrm{p}}$ and $\rho_{\mathrm{p}}$ are the diameter and density of a particle, $\rho_{\mathrm{f}}$ is the density of fluid, $\mu$ is the dynamic viscosity 275 for fluid, $v$ is kinematic viscosity for fluid, $\varepsilon$ is the turbulence dissipation rate. The Stokes numbers of fine 276 particles with diameter of $0.1,1.0,2.5$ and $10 \mu \mathrm{m}$ in three turbulent agglomerators were illustrated in Table 2 . It 277 can be seen that the Stokes numbers of fine particles with diameter less than $2.5 \mu \mathrm{m}$ were all smaller than 1.06 278 in the flow field of three turbulent agglomerators, and most of them were smaller than 1.0, which means their 279 inertia is small and they can follow the flue gas well, so they can enter the backflow areas. However, for particles 280 with diameter of $10 \mu \mathrm{m}$, the Stokes numbers are all greater than 10 , which indicates that their inertia is relatively

281 large, so they tend to maintain their original movement and most of them only move in the main flow area.

282 Besides, the movement of particles is also different in three turbulent agglomerators due to the vortex sheets 283 with different structures and arrangements. In turbulent agglomerator $\# 1$, due to the coupling of vortex sheets 284 with different structures, the motion trajectories of fine particles with different sizes in the flow field are quite 285 different. The fine particles with small sizes $(0.1,1.0,2.5 \mu \mathrm{m})$ are affected by both z-type and cross-type vortex 286 sheets and fluctuate in the $y$-axis direction, thus entering the backflow areas behind the two kinds of vortexes in 287 large quantities. However, the particles with diameter of $10 \mu \mathrm{m}$ are mainly affected by the z-type vortex sheets 288 in front, and the rear cross-type ones have little impact on them, so they hardly enter the backflow areas behind 289 the cross-type vortex sheets. In turbulent agglomerator \#2, owing to the large size of z-type vortex sheets, the 290 intensity of the vortexes generated in the flow field is high and the influence range is large. Therefore, particles 291 with different sizes are all affected by them and fluctuate strongly in the y-axis direction, and some particles 292 with even the size of $10 \mu \mathrm{m}$ can enter the backflow areas behind the vortex sheets. In turbulent agglomerator \#3, 
due to the small size of the cross-type vortex sheets, the vortexes generated in the flow field is weak and the

influence range is small. Therefore, particles with different sizes all have weak fluctuations in the y-axis direction,

and very few particles can enter the backflow areas. Comparing the results, it indicates that the coupling of

different vortex sheets can increase the trajectory difference of fine particles owing to the more disordered flow

field, so as to enhance their relative movement, which is beneficial to their collision and agglomeration. While,

298 in the turbulent agglomerator with only a single type of vortex sheets, the flow field distribution is relatively

more regular, so the difference in the movement trajectories of fine particles is not so obvious and the promotion

300 effect to their collision and agglomeration is relatively weak.

301 3.4.3. Residence time of fine particles in turbulent agglomerators. The residence time of fine particles in the

302 flow field also has a great influence on their collision numbers and agglomeration effect. The longer the residence

303 time of fine particles in the flow field, the more collisions between them may happen, and the more likely they

304 can agglomerate together. So the residence time of fine particles with different sizes in three turbulent

305 agglomerators was also calculated to explore the promotion mechanism of particle agglomeration by different

306 vortex sheets. Besides, that in a flue with the same external structure but containing no vortex sheets was also

307 calculated as a comparison, shown in Figure 11. For each particle size, 5000 particles were selected to calculate

308 the average residence time as the result. It shows that the residence time of fine particles with different sizes in

309 the flue is all relatively short, which is $0.077,0.078,0.079$ and $0.093 \mathrm{~s}$ for the particles with diameters of 0.1 ,

$3101.0,2.5$ and $10 \mu \mathrm{m}$, respectively. It can be inferred that without any vortex sheets, the fine particles can follow

311 the flue gas and move in a straight line in the flue, so they can reach the outlet in a short time. Moreover, since

312 there was no turbulence in the flow field, the movement of fine particles was mainly affected by the drag force

313 of flue gas, which is proportional to the sizes of them. The drag force on fine particles increased with the increase 
314 of their sizes, which made their velocities decrease and residence time extend. In the turbulent agglomerators,

315 the residence time of fine particles with different sizes is longer due to the effect of vortex sheets. In turbulent

316 agglomerator \#1, the residence time of particles with different sizes is all longer than that in turbulent

317 agglomerator $\# 2$ and $\# 3$, and the difference is more obvious as the particle size decreases. For example, for the

318 particles with diameter of $0.1 \mu \mathrm{m}$, the residence time in turbulent agglomerator \#1, \#2 and \#3 is $0.41,0.36$, and

$3190.29 \mathrm{~s}$, and that in $\# 1$ is 0.05 and $0.12 \mathrm{~s}$ longer than in \#2 and \#3 respectively. While for the particles with

320 diameter of $10 \mu \mathrm{m}$, the residence time in turbulent agglomerator $\# 1, \# 2$ and $\# 3$ is $0.27,0.25$ and $0.22 \mathrm{~s}$, and that

321 in \#1 is only 0.02 and $0.05 \mathrm{~s}$ longer than in \#2 and \#3. In addition, the change of particle residence time with

322 particle size in turbulent agglomerators is also different, and the smaller the particle size, the longer it stays in

323 the flow field, which is contrary to that in the flue. This is because the fine particles didn't move along a straight

324 line in the turbulent agglomerators due to the vortex sheets and their trajectories were mainly affected by the

325 turbulence in the flow field. The more disordered of the turbulent flow field, the more violent of the particle

326 fluctuations, and the longer of their movement trajectories and residence time. Fine particles with small sizes

327 had better following performance to the gas flow, so they can fluctuate more violently in the flow field and enter

328 the backflow areas, thus making their movement trajectories and residence time longer. The result indicates that

329 due to the coupling of vortex sheets with different structures, the flow field in turbulent agglomerator \#1 was

330 more disordered, which can make the movement of fine particles more complicated and their residence time

331 longer, thus promoting the collision and agglomeration between them. Moreover, the smaller of fine particles,

332 the more obvious of the promotion effect, which can partly explain the good agglomeration effect of fine particles

333 below $0.1 \mu \mathrm{m}$ in Figure 5 and the obvious improvement of removal efficiency for fine particles below $1.0 \mu \mathrm{m}$ in

334 Figure 8. 
335

336

337

\section{AUTHOR INFORMATION}

\section{Corresponding Author}

\section{CONCLUSIONS} the range below $1.0 \mu \mathrm{m}$.

In this work, the coupling of vortex sheets with different structures in chemical-turbulent agglomeration was propose to improve the agglomeration and removal effect of coal-fired fine particles. Two different types of vortex sheets and three kinds of turbulent agglomerators were designed and manufactured to generate turbulent flow fields. The particle number concentration, size distribution, as well as the particle removal efficiency after chemical-turbulent agglomeration with different turbulent agglomerators were investigated by experiments. The results showed that the coupling of different vortex sheets in turbulent agglomerator can effectively promote the agglomeration and removal effect of fine particles, the number of fine particles below $0.1 \mu \mathrm{m}$ decreased significantly, and the number and mass concentration of fine particles at the outlet of ESP decreased about $67.2 \%$ and $60.5 \%$ respectively. Besides, the improvement of removal efficiency for fine particles was more obvious in

In addition, the flow field distribution, the motion and residence time of fine particles with different sizes in turbulent agglomerators were simulated using CFD method to explore the promotion mechanism by the coupling of different vortex sheets. The results proved that the coupling of z-type and cross-type vortex sheets in chemicalturbulent agglomeration can make the turbulent flow field more disordered, enhance the relative movement of fine particles, and extend their residence time in the flow field, thus promoting the agglomeration and removal effect. This work can provide reference for the deep removal of fine particles in coal-fired processes, especially

in areas with high environmental protection requirements.

Linjun Yang - Key Laboratory for Energy Thermal Conversion and Control of Ministry of Education, 
356 Southeast University, Nanjing 210096, Jiangsu, China; orcid.org/0000-0001-7302-4378; Email:

\section{101010340@seu.edu.cn}

358 Hao Wu - School of Energy and Mechanical Engineering, Nanjing Normal University, Nanjing 210042, China;

359 orcid.org/0000-0001-5128-1306; Email: wu-hao@njnu.edu.cn

360 Authors

361 Zongkang Sun - Key Laboratory for Energy Thermal Conversion and Control of Ministry of Education,

362 Southeast University, Nanjing 210096, Jiangsu, China

363 Xiuwei Ma - Key Laboratory for Energy Thermal Conversion and Control of Ministry of Education, Southeast

364 University, Nanjing 210096, Jiangsu, China

365 Xin Wu - Key Laboratory for Energy Thermal Conversion and Control of Ministry of Education, Southeast

366 University, Nanjing 210096, Jiangsu, China

367 Notes

368 The authors declare no competing financial interest.

369 ACKNOWLEDGMENTS

370 This work was supported by the National Key Research and Development Program of China

371 (No.2016YFB0600602) and the Scientific Research Foundation of Graduate School of Southeast University

372 (No.3203009749).

373 REFERENCES

374 (1) Kwauk, M. Emerging particle science and technology in China. Powder Technol. 2003, 137 (1-2), 2-28.

375 (2) BP, P. L. $\quad$ C. $\quad$ BP statistical review of world energy 2019 [Online].

376 https://www.bp.com/content/dam/bp/country-sites/zh cn/china/home/reports/statistical-review-of-world- 
energy/2019/2019srbook.pdf. (Accessed March 10, 2020).

(3) Yi, H. H.; Hao, J. M.; Duan, L.; Li, X. H.; Guo, X. M. Characteristics of inhalable particulate matter concentration and size distribution from power plants in China. J. Air Waste Manage. Assoc. 2006, 56 (9), 12431251.

(4) Yi, H. H.; Hao, J. M.; Duan, L.; Tang, X. L.; Ning, P.; Li, X. H. Fine particle and trace element emissions from an anthracite coal-fired power plant equipped with a bag-house in China. Fuel 2008, 87, 2050-2057.

(5) Latif, M. T.; Othman, M.; Idris, N.; Juneng, L.; Abdullah, A. M.; Hamzah, W. P.; et al. Impact of regional haze towards air quality in Malaysia: A review. Atmos. Environ. 2018, 117, $28-44$.

(6) Yao, Q.; Li, S. Q.; Xu, H. W.; Zhuo, J. K.; Song, Q. Studies on formation and control of combustion particulate matter in China: a review. Energy 2009, 34 (9), 1296-1309.

(7) Zhuang, X. L.; Wang, Y. S.; He, H.; Liu, J. G.; Wang, X. M.; Zhu, T. Y.; et al. Haze insights and mitigation

in China: An overview. J. Environ. Sci. 2014, 26, 2-12.

(8) World health organization. WHO air quality guidelines global update 2005. Bonn, Germany, 2005.

(9) Saarnio, K.; Frey, A.; Niemi, J. V.; Timonen, H.; Rönkkö, T.; Karjalainen, P.; et al. Chemical composition

391 and size of particles in emissions of a coal-fired power plant with flue gas desulfurization. J. Aerosol. Sci. 2014,

\section{$73,14-26$.}

393 (10) Gu, J. X.; Bai, Z. P.; Li, W. F.; Wu, L. P.; Liu, A. X.; Dong, H. Y.; et al. Chemical composition of PM 2.5

394 during winter in Tianjin, China. Particuology 2011, 9 (3), 215-221.

395 (11) Yang, L. X.; Cheng, S. H.; Wang, X. F.; Nie, W.; Xu, P. J.; Gao, X. M.; et al. Source identification and health impact of $\mathrm{PM}_{2.5}$ in a heavily polluted urban atmosphere in China. Atmos. Environ. 2013, 75, 265-269.

397 (12) Thonglek, V.; Kiatsiriroat, T. Agglomeration of sub-micron particles by a nonthermal plasma electrostatic 
398

399

400

401

402

403

411 particles from a 330 MW PC-fired boiler. Fuel 2016, 165, 86-93.

412 (19) Dong, M.; Zhou, F.; Shang, Y.; Li, S. F. Numerical study on electrohydrodynamic flow and fine-particle

413 collection efficiency in a spike electrode-plate electrostatic precipitator. Powder Technol. 2019, 351, 71-83.

414 (20) Zu, K.; Yao, Y.; Cai, M.; Zhao, F.; Cheng, D. L. Modeling and experimental study on acoustic

precipitator. J. Electrost. 2014, 72 (1), 33-38.

(13) Lin, W. Y.; Chang, Y. Y.; Lien, C. T.; Kuo, C. W. Separation characteristics of submicron particles in an electrostatic precipitator with alternating electric field corona charger. Aerosol Sci. Technol. 2011, 45 (3), $393-$ 400.

(14) Guo, Y. Q.; Zhang, J. Y.; Zhao, Y. C.; Wang, S. L.; Jiang, C.; Zheng, C. G. Chemical agglomeration of fine particles in coal combustion flue gas: Experimental evaluation. Fuel 2017, 203 (1), 557-569.

(15) Liu, Y.; Hu, B.; Zhou, L.; Jiang, Y. Z.; Yang, L. J. Improving the removal of fine particles with an electrostatic precipitator by chemical agglomeration. Energy Fuels 2016, 30 (10), 8441-8447.

(16) Yang, L. J.; Bao, J. J.; Yan, J. P.; Liu, J. H.; Song, S. J.; Fan, F. X. Removal of fine particles in wet flue gas desulfurization system by heterogeneous condensation. Chem. Eng. J. 2010, 156, 25-32.

(17) Heidenreich, S.; Ebert, F. Condensational droplet growth as a preconditioning technique for the separation of submicron particles from gases. Chem. Eng. Process. 1995, 34 (3), 235-244.

(18) Chen, D. L.; Wu, K.; Mi, J. C. Experimental investigation of aerodynamic agglomeration of fine ash

415 agglomeration for dust particle removal. J. Aerosol. Sci. 2017, 114, 62-76.

416 (21) Liu, J. Z.; Wang, J.; Zhang, G. X.; Zhou, J. H.; Cen, K. F. Frequency comparative study of coal-fired fly

417 ash acoustic agglomeration. J. Environ. Sci. 2011, 23 (11), 1845-1851.

418 (22) Yan, J. P.; Chen, L. Q.; Yang, L. J. Combined effect of acoustic agglomeration and vapor condensation on 
419 fine particles removal. Chem. Eng. J. 2016, 290, 319-327.

420 (23) Luo, Z. Y.; Chen, H.; Wang, T.; Zhou, D.; Lu, M. S.; He, M. C.; et al. Agglomeration and capture of fine

421 particles in the coupling effect of pulsed corona discharge and acoustic wave enhanced by spray droplets. Powder 422 Technol. 2017, 312, 21-28.

423 (24) Yan, J. P.; Chen, L. Q.; Li, Z. Removal of fine particles from coal combustion in the combined effect of 424 acoustic agglomeration and seed droplets with wetting agent. Fuel 2016, 165, 316-323.

425 (25) Zhang, G. X.; Zhou, T. T.; Zhang, L. L.; Wang, J. Q.; Chi, Z. H.; Eric, H. Improving acoustic agglomeration 426 efficiency of coal-fired fly-ash particles by addition of liquid binders. Chem. Eng. J. 2018, 334, 891-899.

427 (26) Yan, J. P.; Lin, Q.; Zhao, S. H.; Chen, L. Q. Effect of seed nuclei combined with acoustic field on fine 428 particles removal. Powder Technol. 2018, 340, 8-16.

429 (27) Hu, B.; Yi, Y.; Liang, C.; Yuan, Z. L.; Szczepan, R.; Yang, L. J. Experimental study on particles 430 agglomeration by chemical and turbulent agglomeration before electrostatic precipitators. Powder Technol. 2018, $431335(15), 186-194$.

432 (28) Sun, Z. K.; Yang, L. J.; Shen, A.; Hu, B.; Wang, X. B.; Wu, H. Improving the removal of fine particles 433 from coal combustion in the effect of turbulent agglomeration enhanced by chemical spray. Fuel 2018, 234,

(29) Ho, C. A.; Sommerfeld, M. Modelling of micro-particle agglomeration in turbulent flows. Chem. Eng. Sci.

437 (30) Asanakham, A.; Kiatsiriroat, T. Use of bluff-body for enhancing submicron particle agglomeration in plasma field. Part. Sci. Technol. 2018, 36 (2), 123-130.

439 (31) Afkhami, M.; Hassanpour, A.; Fairweather, M.; Njobuenwu, D. O. Fully coupled LES-DEM of particle 
440 interaction and agglomeration in a turbulent channel flow. Comput. Chem. Eng. 2015, 78, 24-38.

441 (32) Breuer, M.; Almohammed, N. Modeling and simulation of particle agglomeration in turbulent flows using

442 a hard-sphere model with deterministic collision detection and enhanced structure models. Int. J. Multiph. Flow

$443 \mathbf{2 0 1 5}, 73,171-206$.

444 (33) White, H. J. Particle charging in electrostatic precipitation. Transactions of the American Institute of

$445 \quad$ Electrical Engineers. 1951, 70 (2), 1186-1191.

446 (34) Fluent INC. FLUENT 6.3 user’s guide. Fluent documentation, 2006.

447 (35) Pope, S. B. Turbulent flow. Cambridge University Press: Cambridge, 2000.

448 (36) Spalding, D. B. The combustion of liquid fuels. Symposium (International) on Combustion 1953, 4 (1),

$449 \quad 847-864$. 


$$
e^{e^{r^{2}}}
$$




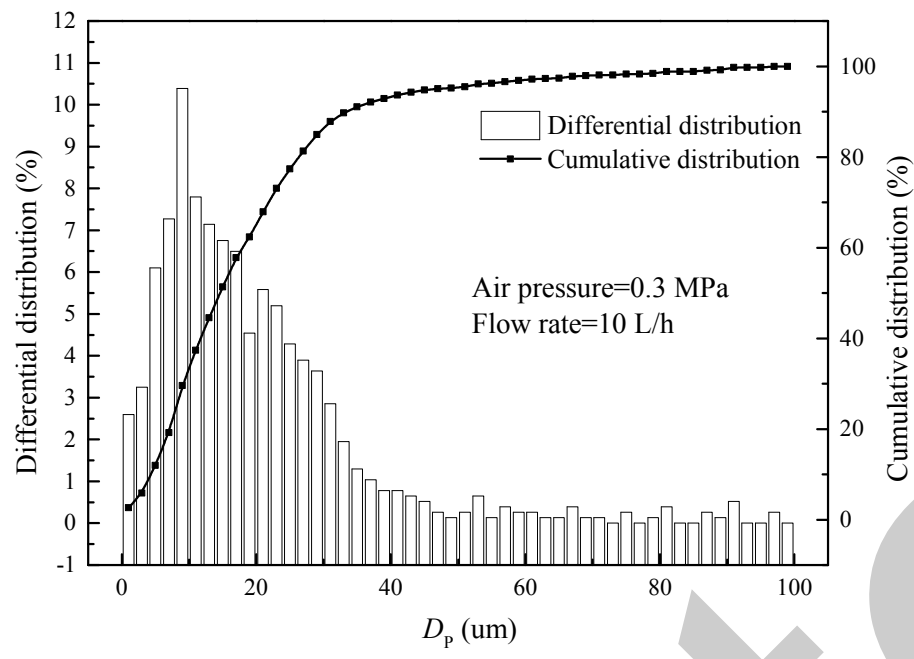

Figure 2. Size distribution of chemical droplets. 
Page 25 of 36

Energy \& Fuels

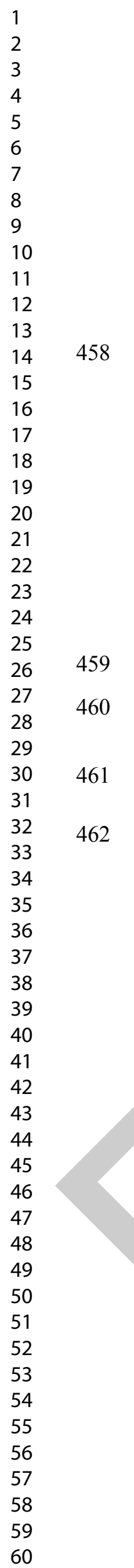

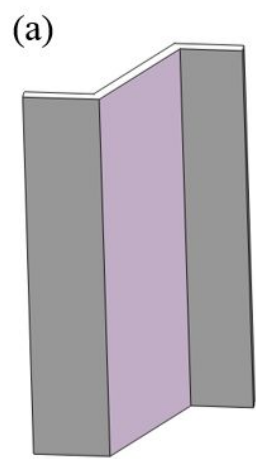

(c)

$\# 1$ :
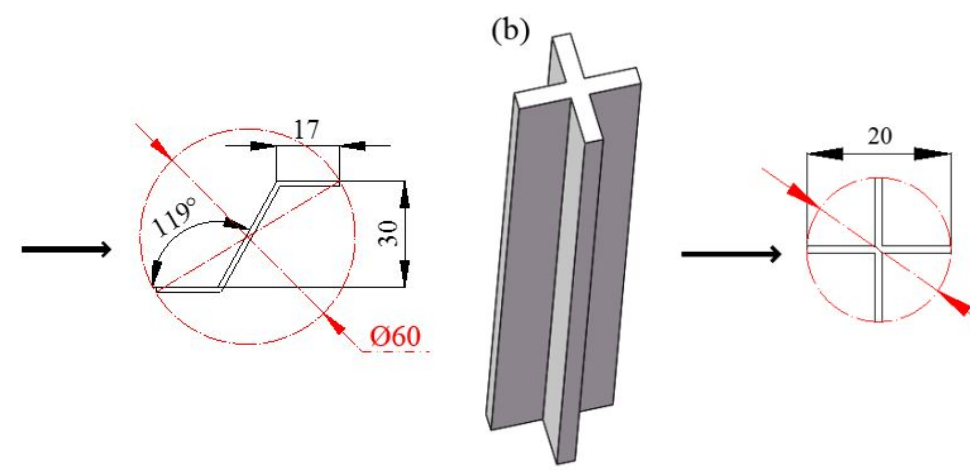

$\varnothing 20$

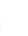

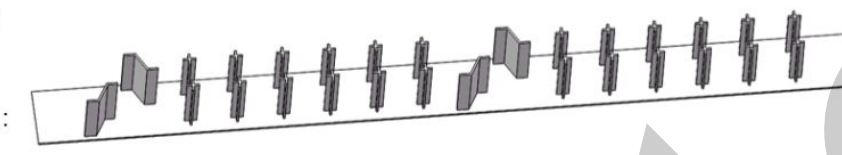

\#2:

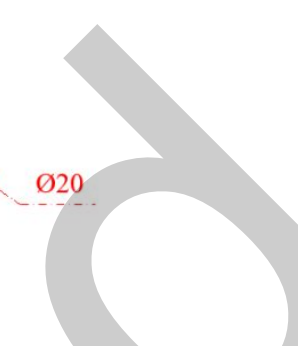

\#3: $\mathrm{x}$.

Figure 3. Structures of (a) z-type vortex sheets, (b) cross-type vortex sheets and (c) the arrangements in three turbulent agglomerators.

ACS Paragon Plus Environment 


$$
e^{e^{x^{r^{e^{2}}}}}
$$




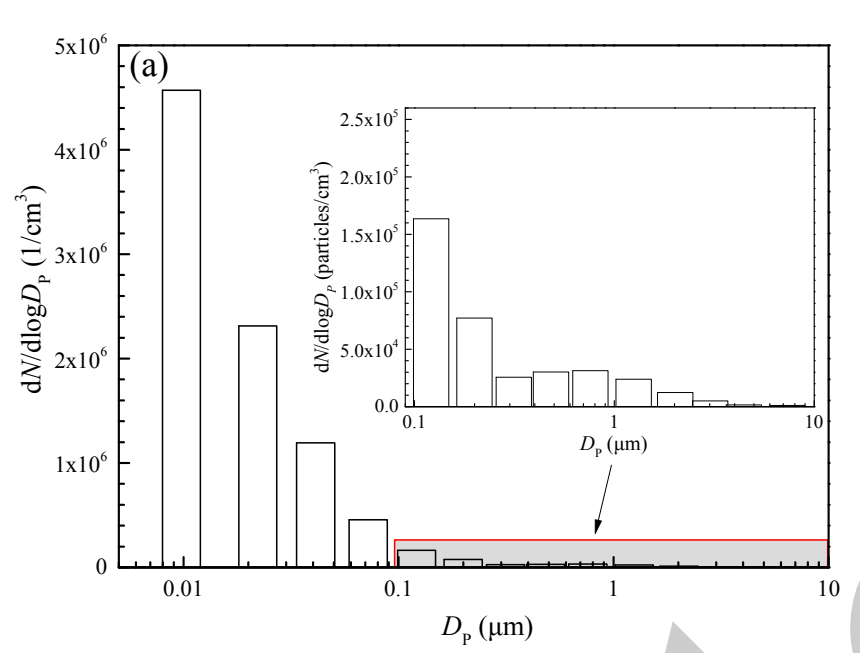

466

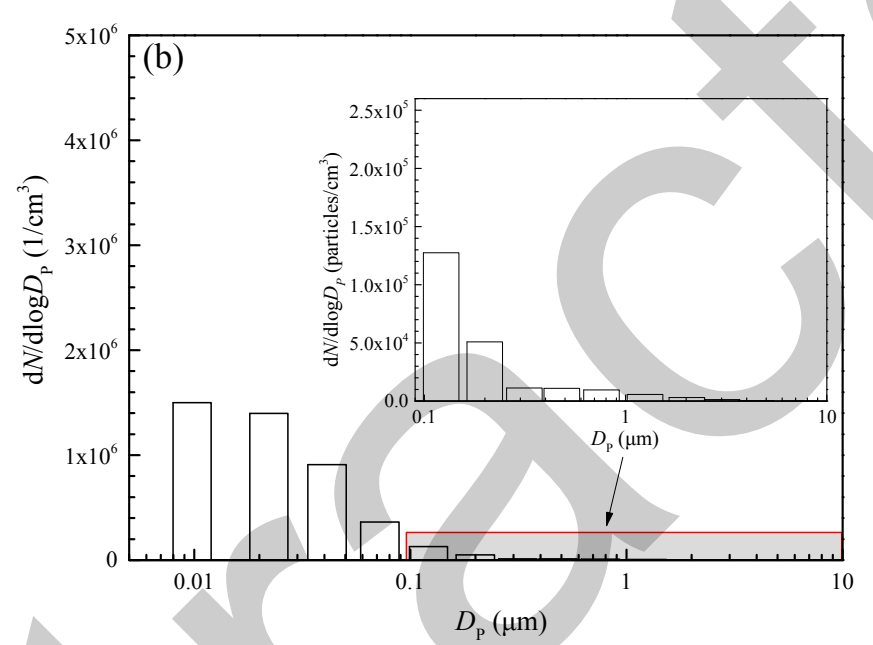

467 
Energy \& Fuels

Page 28 of 36

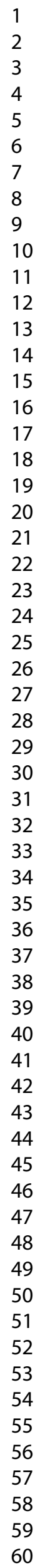

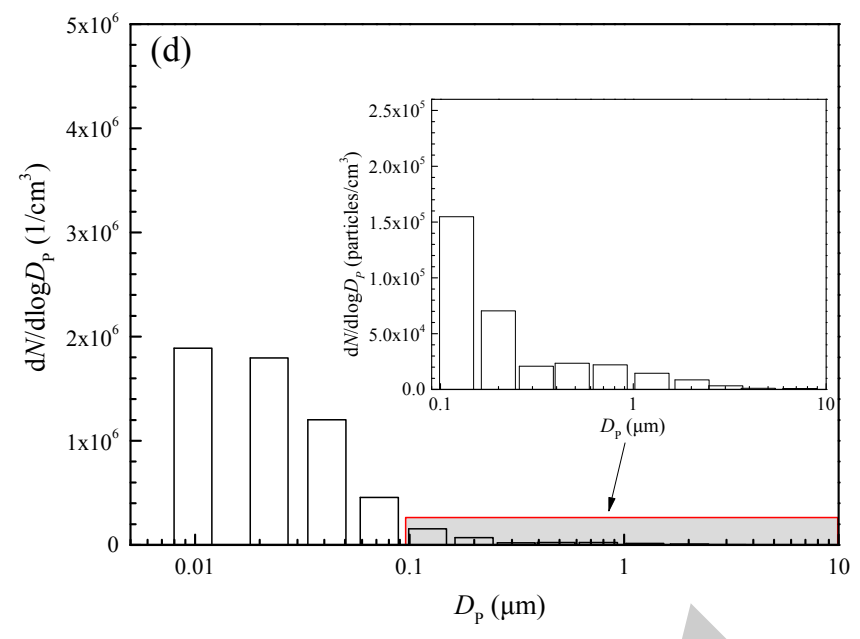

Figure 5. Particle size distributions in (a) original flue gas, (b) after turbulent agglomerator \#1, (c) \#2 and (d)

471

472
\#3.

5

ACS Paragon Plus Environment 


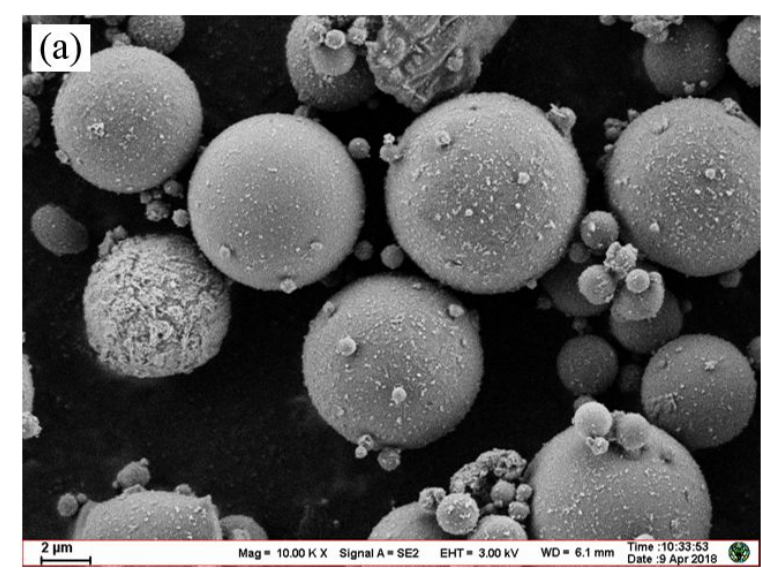

474

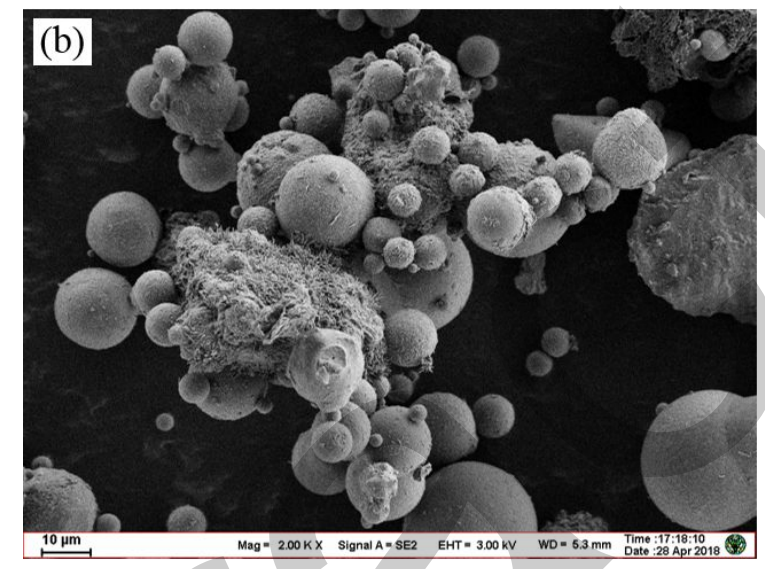




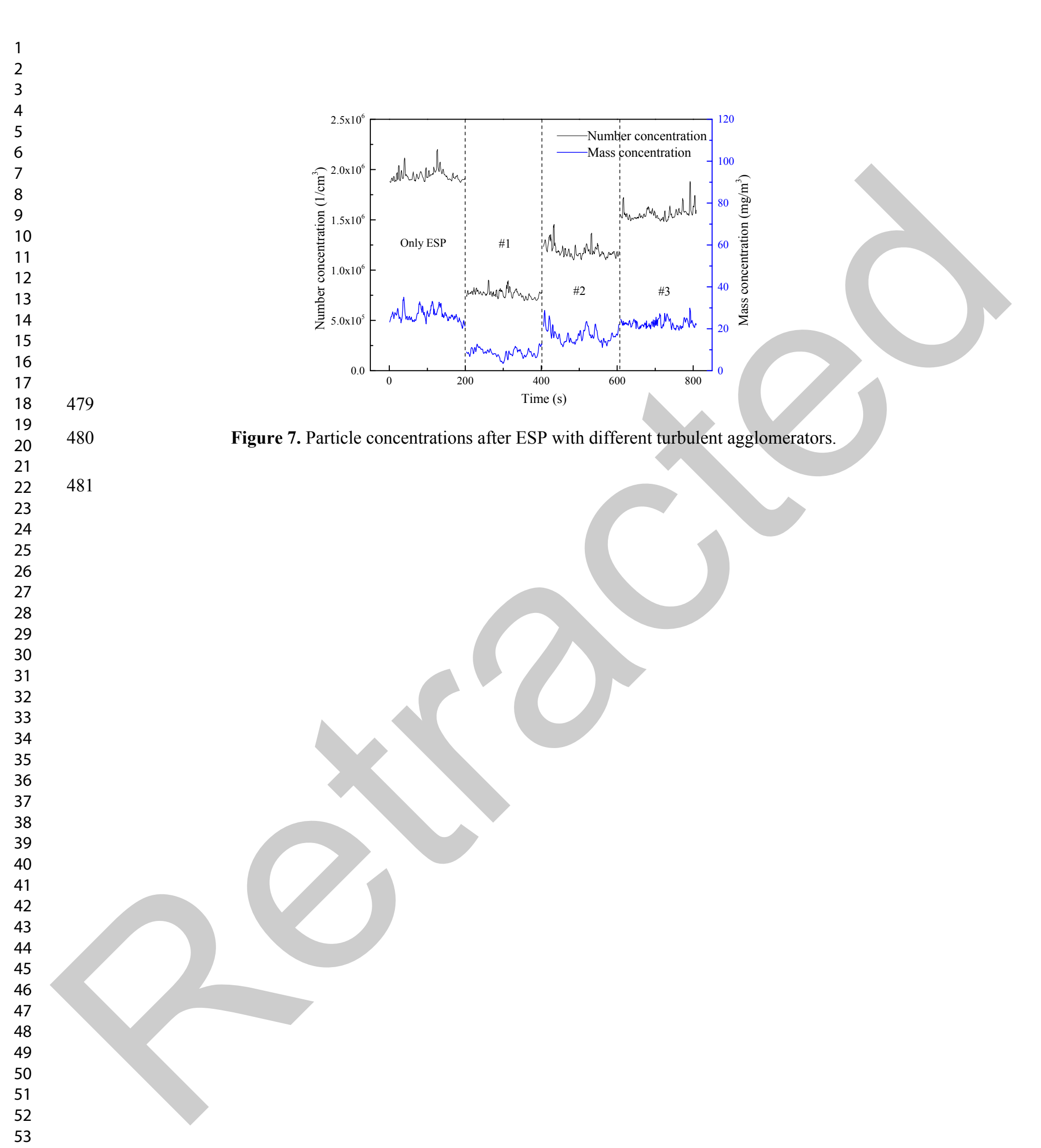




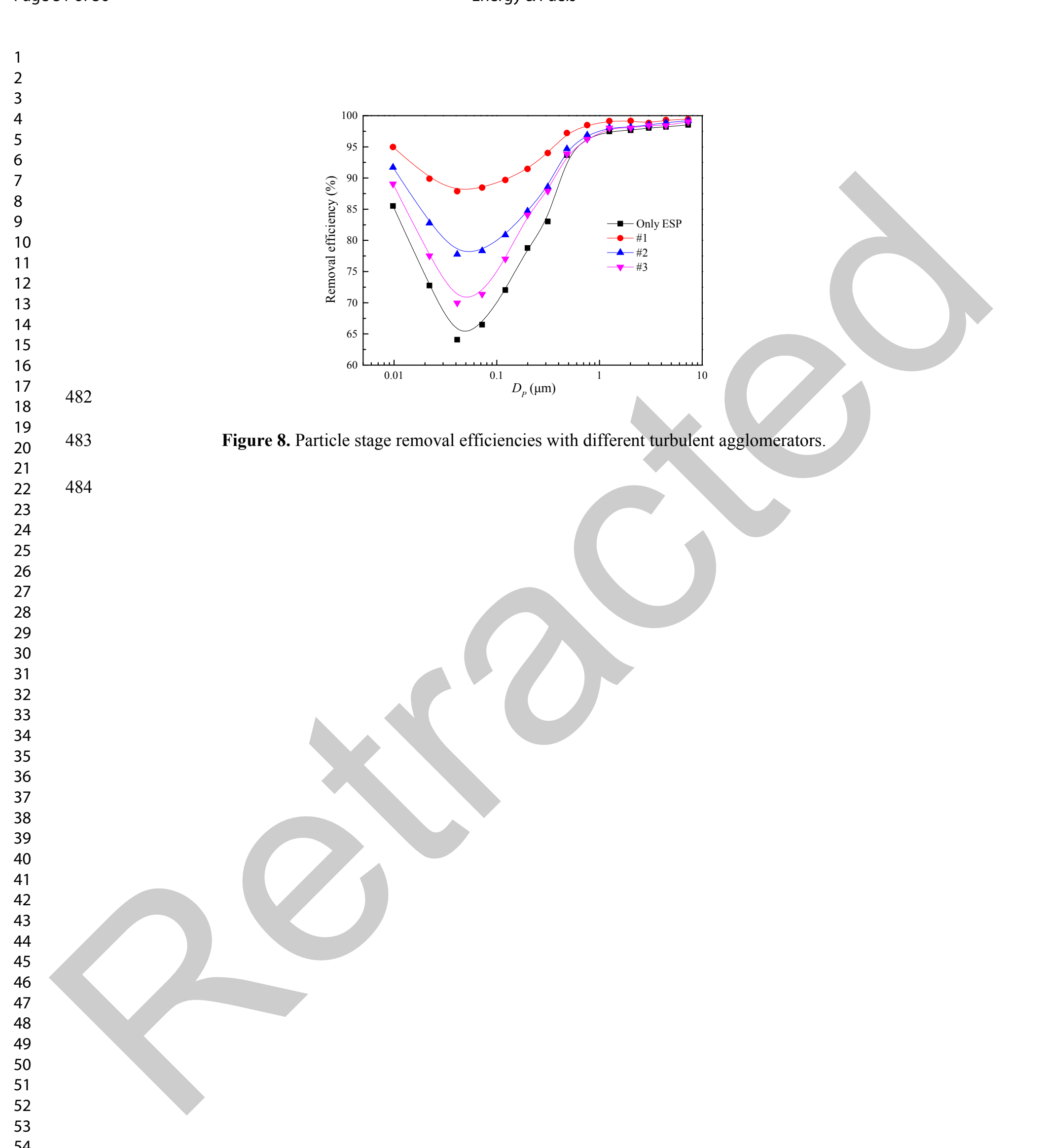


<smiles></smiles> 
(a)

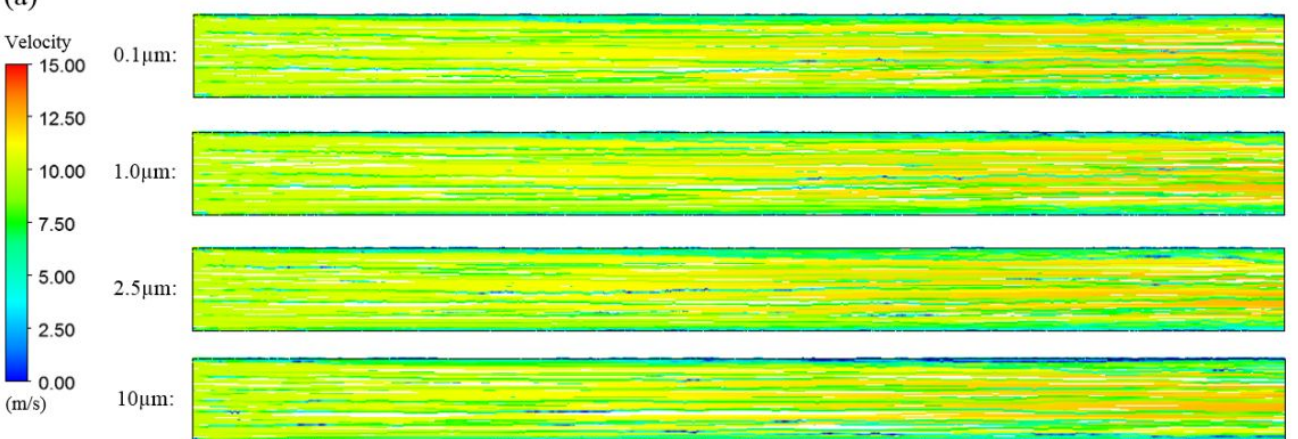

488

(b)
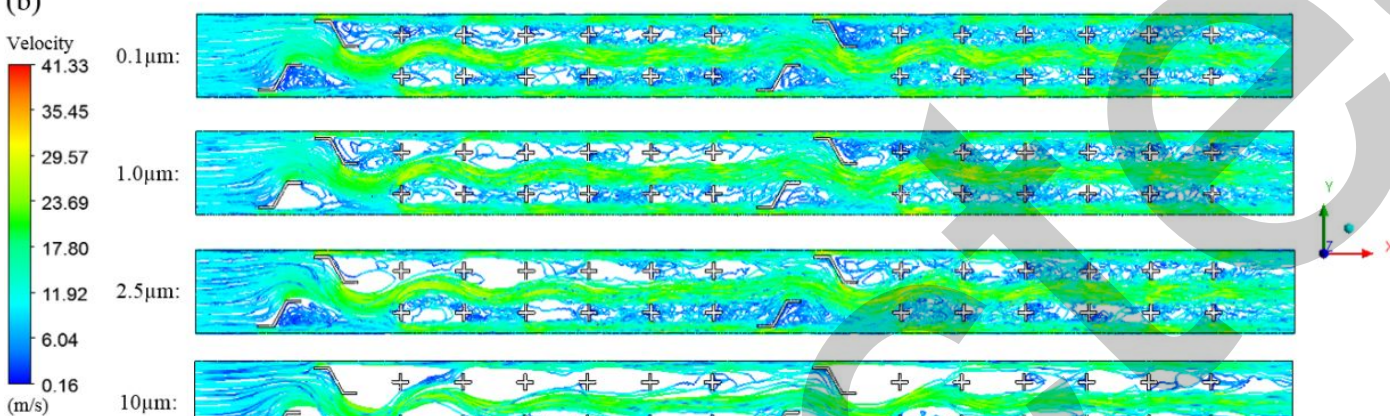

(c)
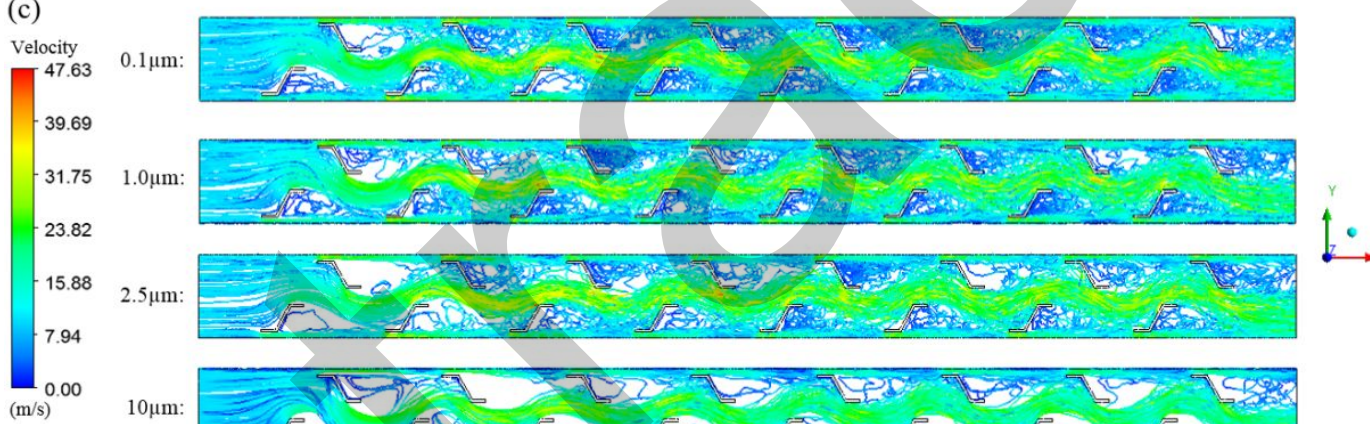

(d)

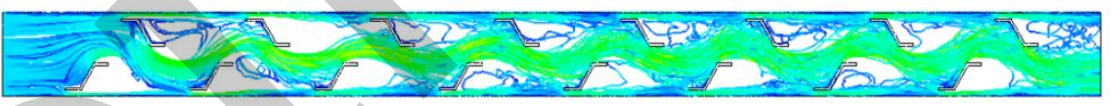

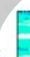
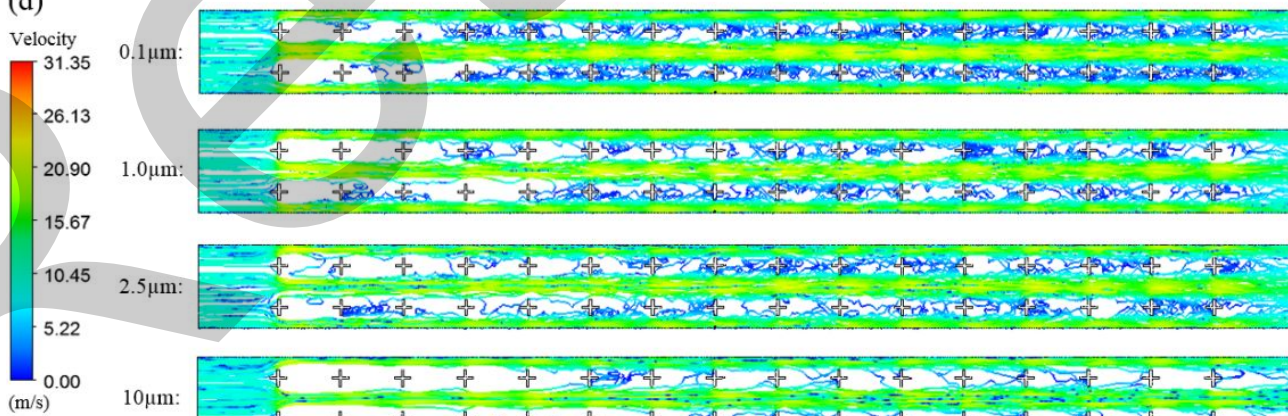

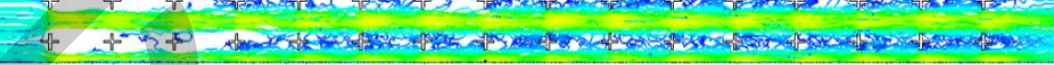

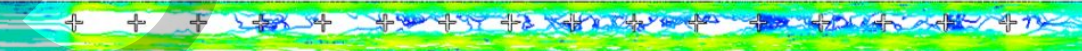

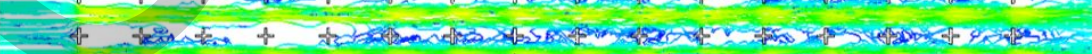
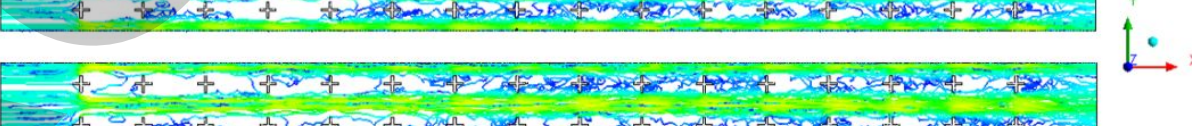

$10 \mu \mathrm{m}:$

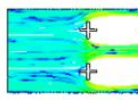

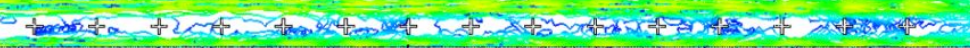

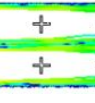

(d) \#3. 


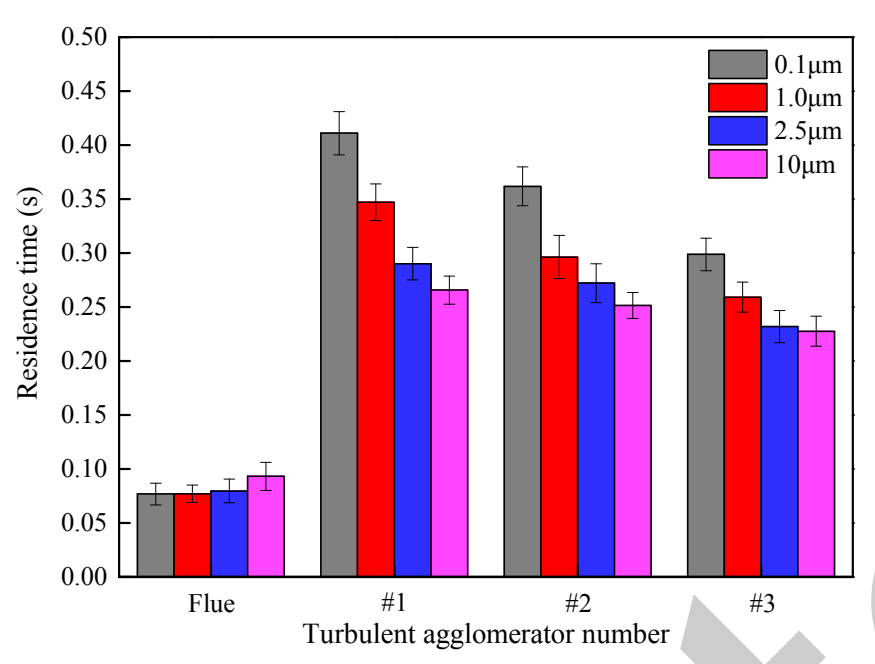

Figure 11. Residence time of particles in the flue and three turbulent agglomerators. 


$$
e^{e^{2 x^{2}}}
$$




$$
e^{e^{x^{e^{e^{e}}}}}
$$

